\title{
The Quantitative Analysis of Science Policy Subject in China
}

\author{
Deyi Kong
}

\author{
School of Humanities \& Law , Northeastern University , Shenyang , China \\ kongdeyi_kdy@sohu.com
}

\section{Key word: Popular Science; Science Policy; Policy Subject; Policy Text; Quantitative Analysis}

\begin{abstract}
Taking the 511 popular science policies promulgated by China from 1994 to 2013 as the research sample, this paper makes a statistic analysis on the quantity of policy dispatch subject, and discussed the constitution of policy subject and the condition of separate or joint dispatch on this basis. The study shows that the number of development tendency policy was relatively stable from 1994 to 2005, and the trend had an obvious surge from 2006 to 2013, as compared with previous period. Generally speaking, it proves that its developing characteristics are progressively and explosively combined; the popular science subject of China was up to 42 . The number of separate dispatch was mainly issued by Ministry of Land and Resource, State Administration of Traditional Chinese Medicine and Ministry of Agriculture. In the policy text of united dispatch, priority was given to two and three dispatch subjects. Overall, the policy decision maker gives priority to single department dispatch. As the scale of joint dispatch subject increases gradually, cooperation between policy subjects can be further enhanced.
\end{abstract}

\section{Introduction}

" 21 st century is a period of sustainable development, in which century people rely on knowledge innovation theory and knowledge innovation application comprehensively.Besides, the scientific knowledge was known as one of the most important production factors as well as an important platform in dissemination of scientific culture and the heritage of scientific knowledge, so it has become the safeguard mechanism of economy and society development." [1] "Popular science is a social public welfare undertaking. By making and improving the popular science, the government builds the social environment in favor of the spread of science, in order to promote the development of popular science career." [2]As an important means to standardize and regulate the popular science work, popular science policy plays a huge role in the popular science. Popular science policy refers to "laws, laws and regulations, regulations, rules and policy documents issued by legislature in each level and government."[3] Seen from the popular science policy unit level, it means "the pop policy issued by the central committee of Communist Party of China; the State Council and NPC; the ministries and commissions made by MOST and united or separated departments; also the local policy made by province and city."[4] Popular science policy was divided into specialized one and relative one from the form, "specialized popular science policy was the relative policy made to popular science specially, although the relative popular science policy was not the popular science policy specially, many aspects about popular science works were involved in the content of policy."[5] Since the reform and opening up, Chinese popular science policy has participated in making the subject, which is gradually increasing; however, as the complexity degree in the aspect of policy-making increases, the implementation deepens,, the network structure of policy-making subject is complicated, it is thus objectively necessary to build the popular science policy cooperation network and cooperation mechanism. Therefore, research on the establishment condition of Chinese policy subject has important significance in perfecting Chinese popular science policy system and improving the influence of policy system. 


\section{Sample Selection and Screening}

Sample Source. When searching the source of policy text, the present popular science policy text data mainly comes from the laws, regulations and the legal information network of judicial interpretations library of Peking University. [6] Meanwhile, the policy test published by government official website was selected to prevent omission as supplement, in order to ensure the authority and the comprehensiveness policy text selection. The selection of policy was publicly promulgated, excluding the policy text not publicly promulgated. Sample selection basically covered the central popular science policy text, which provided sufficient data for the future study of later popular science.

Determining the Scope of the Time. The retrieval time ranged from January 1, 1994 to December 31, 2013. The several opinions on strengthening science and technology popularization issued on December 5, 1994 was the first programmatic document, which comprehensively discusses the popular science works since the founding of new China, and it is also the first time for China to guide the work of popular science of official document.[7] Therefore, the retrieval time was set in 1994. In order to guarantee the accuracy of the research, the starting time and deadline were respectively set in January 1, 1994 and December 31, 2013.

Searching Keywords. In the process of policy text retrieval, the study firstly takes the popularity of science and technology as the keywords to do fuzzy searching in the full text, and a total of 2936 terms of relevant laws and regulations on popularization of science and technology were searched. To make this study more accurate and further narrow the scope, the study set the popularity of science and technology as the keywords to do precise quadratic search, as a result, a total of 733 items on relevant policy text were found.

Policy Text Filtering and Sorting. To ensure the selected policy text is accurate and representative, and to improve the pertinence of this study, the researched policy text was obtained and worked out according to the following principles. First, only the policy text issued by the Central was adopted, namely, the dispatch units were the Central Committee of the Communist Party of China, the national People's Congress, the standing committee of the National People's Congress, the state council and its direct affiliated institutions, because the application scope of laws and regulations had limitations as different regions had different development status with respect to the career of popularization of science and technology, making the local policy become no representative property, and thus they were not adopted. Second, the retrieval policy type was mainly the laws and regulations, outline, notification, opinion, planning, announcement and so on. Somehow, the reply, industry standards and other documents were not included. Again, the policy text with low correlation of the popula science and technology details, the policy was not stipulated directly or the scientific measures in policy clause was not clearly reflected, and the dispatch units' attitude to scientific development were not included as well. Eventually, the policy text transmitted or repeated as well as those with little research significance were eliminated, such as science program broadcast time notification, individual winners bulletin, popular science base announcement, notice of meeting and training time and so on. After the policy text was sorted with the adjustment and improvement of collection result, the final number of efficient policy was 511.

\section{The Annual Policy Text Analysis}

Statistic analysis was made according to the annual policy published of screening sample, the number of popular science policy and growth trends issued each year by China was shown in Fig. 1. What's more, the number of science policy text had oscillating type growth trend since 1994, the development trend from 1994 to 2005 was stable, and an obvious surge trend was shown from 2006 to 2013 as compared with the data of previous period, which can be verified from the annual number of published paper. The average annual number of published paper was 26.4 from 1994 to 2013, from which the annual number was 5.58 from 1994 to 2005 and 57.63 from 2006 to 2013, 10.32 times than previous period. It is not hard to find that several obvious growth intervals were shown in 
Fig. 1, which was 2002 to 2003, 2005 to 2007, 2011 to 2013 respectively. The number of science policy text issued in 2003 had a breakthrough of single digits for the first time as a number of 11, which conformed to the actual situation of the development of Chinese science. In June 2002, China promulgated the first legal document, which focused on the work of popular science, namely, the popularization of science and technology law of the People's Republic of China. Chinese popular science had legal protection when it was issued, representing that the work of Chinese popular science had entered a new stage. it was also one of the main reasons for the increasing number of policy text of Chinese popular science. Scientific quality guidelines issued in 2006 marked that the official civil scientific literacy construction of China has been brought into general situation of our whole party and nation. The new historical period started with government promotion and all-people participation. According to the guiding ideology scientific quality outline, its relative necessary accessory policy emerged at the right moment as bamboo shoots after a spring rain like mushrooms after rain, the National 12th Five-Year Plan was issued by the Ministry of Science and Technology in July 2001. These heavyweight policies had a profound impact on the development of Chinese popular science work, also stimulated the increasing number of dispatch developed from 44 in 2011 to 79 in 2012, what's more, 88 in 2013. The number of Chinese popular science policy dispatch has shown absolutely growth trend and presented a certain regularity, which could be seen in Fig. 1, meaning the year of national important or strategic policy documents would become the starting point of surging number of popular science policy, the number of dispatch in the year ensuing got bigger promotion than last year, meaning some guiding policy documents made which was based on national strategic and long-term considering wouldn't produce immediate policy reaction on its matching popular science, because certain time difference was needed as transition, which was a process of accumulation, transition, impact.

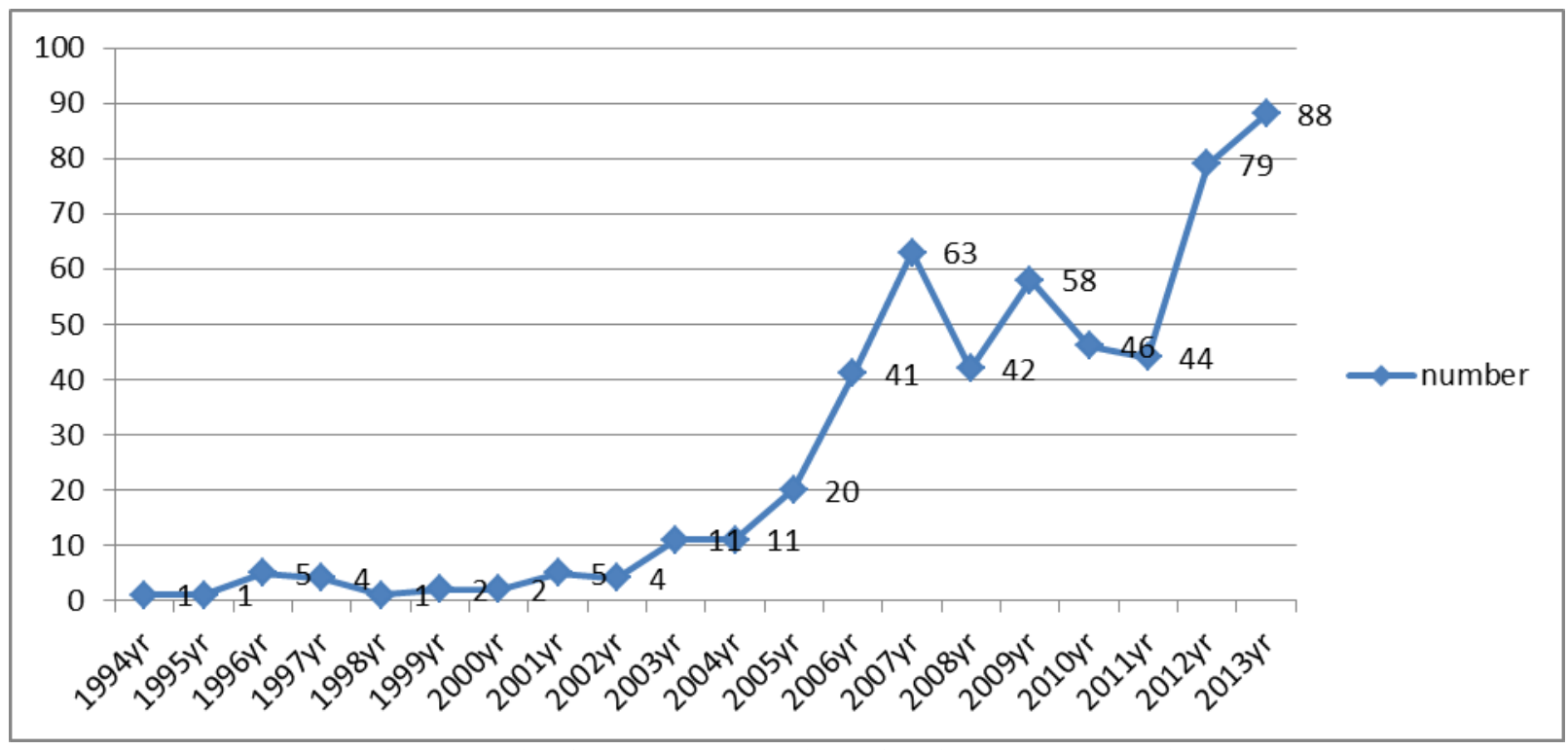

Fig. 1 graph of the annual number of Chinese popular science text

\section{Descriptive Text Analysis of Policy Dispatch Subject}

In the legal sense, "representation institutions, administrative heads of government, administrative institution, independent regulatory agencies or a variety of agents are the subject of policy-making."[8] From the general sense, "policy subject can be simply defined as individuals, groups or organizations who are directly or indirectly involved in the process of policy making." [9] However, the definition of policy subject in this paper used Guowen's definition to it (2010), who thought policy subject (policy activists) was directly or indirectly participated in policy formulation, implementation, evaluation and monitoring of individual, group or organization.[10] Based on this 
definition, policy subject was divided into dispatch organization on two conditions of independent dispatch and unit dispatch in this paper.

The composition of separate policy dispatch subject and analysis of dispatch number. The popular science subject of China made separately was up to 42, as shown in Table 1 . According to the authority, it could be divided to three levels: the first level for the National People's Congress and central China; the second level for the state council; the third level for ministries and commission under the state council and the department of the directly affiliated institutions and some other dispatch departments. The most effectual legal document issued by NPC and the Standing Committee of the National People's Congress was only one item, accounting for about $0.24 \%$ of the total. In addition, the administrative legal policies promulgated by state council was 27 items, accounting for about $6.51 \%$ of the total, the number of separate dispatch issued by various ministries and commissions under the state council, directly affiliated institutions and other dispatch subjects was 387 items, accounting for about $93.25 \%$, of which 208 items was from CAST, accounting for about $50.12 \%$. In addition, there were also many dispatch subjects issued by the Ministry of Land and ResourcesMinistry of Land and Resourcess, Ministry of Science and Technology, state Administration of Traditional Chinese Medicine, and Ministry of Agriculture. Almost no specialized science policy was in a policy vacuum before 1994. The number of Chinese popular science policy was less from 1994 to 2005, especially before 2002, the policy-making was mainly undertook by few departments likes Ministry of Science and Technology, Ministry of Land and Resources, technological association, ministry of culture, other departments were barely involved in policy-making. With Chinese science popularization law promulgated in 2002, certain promotion could be seen. From 2002 to 2005, the number of popular science policy and policy-making departments had an obvious increase. After 2006, as the increasing efforts to improve the quality of citizens in China, Ministry of Finance, State Administration of Quality Supervision, State Forestry Bureau Multidisciplinary were added to participate in the future of popular science-making, suddenly emerged so many departments involved in popular science policy-making exploded the number of policies and policy-making departments. The science policy in China was at the intensive development state from 2006 to 2013, which had close contact with encouraging and attaching importance to science and technology by our country and relative strategic deployment of improving the quality of citizens, also those key policies who had landmark significance, which has produced important influence on the development of popular science in China.

Table 1 Composition of Separate Policy Dispatch Subject and Analysis of Dispatch Number of Nation

\begin{tabular}{|c|c|c|c|c|c|c|c|c|c|c|c|c|}
\hline SUBJECK & $94(95)$ & $96(97)$ & 98(99) & $00(01)$ & $02(03)$ & $04(05)$ & $06(07)$ & $08(09)$ & $10(11)$ & 12(13) & SUM & PET \\
\hline NPC & & & & & 1 & & & & & & 1 & $0.24 \%$ \\
\hline CSC & & & & & & (2) & $4(7)$ & 1(1) & $1(5)$ & 5(1) & 27 & $6.51 \%$ \\
\hline MOST & & (1) & & 1(1) & (2) & $1(2)$ & 2 & $1(1)$ & $1(6)$ & 5(3) & 27 & $6.51 \%$ \\
\hline MOA & & & & & (1) & 1 & 2 & 2 & $2(2)$ & $1(7)$ & 18 & $4.34 \%$ \\
\hline SATCM & & & & & & 1 & & $2(2)$ & $2(6)$ & 4(5) & 22 & $5.30 \%$ \\
\hline SFPC & & & & & & & & & & (1) & 1 & $0.24 \%$ \\
\hline MOLR & & & 1 & & & 1(1) & 1 & 1（6) & 3(4) & $3(7)$ & 28 & $6.75 \%$ \\
\hline AQSIQ & & & & & & & 1 & & & (1) & 2 & $0.48 \%$ \\
\hline MOE & & & & & & & & & & 1（1） & 2 & $0.48 \%$ \\
\hline MOHURD & & & & & & & & & & (1) & 1 & $0.24 \%$ \\
\hline MOC & & & & & & & & & & (1) & 1 & $0.24 \%$ \\
\hline CAS & & & & (1) & (1) & & & & & (1) & 3 & $0.72 \%$ \\
\hline SGA & & & & & & & & & (1) & 2(1) & 4 & $0.96 \%$ \\
\hline
\end{tabular}




\begin{tabular}{|c|c|c|c|c|c|c|c|c|c|c|c|c|}
\hline SFA & & & & & & & 1 & & & 1(1) & 3 & $0.72 \%$ \\
\hline$\overline{\mathrm{CMA}}$ & & & & & & & (1) & & $5(2)$ & (1) & 9 & $2.17 \%$ \\
\hline CAST & & & (1) & & 1 & (7) & $10(34)$ & $25(29)$ & 22 & $41(38)$ & 208 & $50.12 \%$ \\
\hline NSWO & & & & & & & & (1) & 1 & (3) & 5 & $1.20 \%$ \\
\hline GAPP & & & & & & & & & & 1 & 1 & $0.24 \%$ \\
\hline GAOSC & & & & & & 1 & 1 & & & 1 & 3 & $0.72 \%$ \\
\hline NSQWG & & & & & & & 4(2) & & (1) & & 7 & $1.69 \%$ \\
\hline CSB & & & & & & & & (1) & $1(2)$ & & 4 & $0.96 \%$ \\
\hline NSGW & & & & & & & & & (1) & & 1 & $0.24 \%$ \\
\hline SFDA & & & & & & 1 & & (1) & 1 & & 3 & $0.72 \%$ \\
\hline NSSOC & & & & & & & & & (1) & (1) & 2 & $0.48 \%$ \\
\hline MOCA & & & & & & & & (2) & & & 2 & $0.48 \%$ \\
\hline MOF & & & & & & & (1) & (1) & & & 2 & $0.48 \%$ \\
\hline $\mathrm{MOH}$ & & & & & & & & $1(2)$ & & 1 & 3 & $0.72 \%$ \\
\hline GIB & & & & & & & & (1) & & & 1 & $0.24 \%$ \\
\hline MOEP & & & & & & & & (1) & (1) & & 2 & $0.48 \%$ \\
\hline CSGPC & & & & & & & & 1(1) & & & 2 & $0.48 \%$ \\
\hline MWR & & & & & & & 1 & 1 & & & 2 & $0.48 \%$ \\
\hline SEPA & & & & & & 1(1) & $2(1)$ & & & & 5 & $1.20 \%$ \\
\hline STMB & & & & & & & $1(1)$ & & 1 & & 3 & $0.72 \%$ \\
\hline SAWS & & & & & & & 1 & & & & 1 & $0.24 \%$ \\
\hline $\mathrm{MC}$ & & & & & 1 & (1) & & & & & 2 & $0.48 \%$ \\
\hline MDC & & 1 & & & & & 1 & & & & 2 & $0.48 \%$ \\
\hline MOPI & & 1 & & & & & & & & & 1 & $0.24 \%$ \\
\hline SBCR & & & & & & & & & & & & $0.00 \%$ \\
\hline MLSS & (1) & & & & & & & & & & 1 & $0.24 \%$ \\
\hline NSTAO & & & & & & (1) & & & & & 1 & $0.24 \%$ \\
\hline CLSS & & & & & & 1 & & & & & 1 & $0.24 \%$ \\
\hline SARFT & & & & & (1) & & & & & & 1 & $0.24 \%$ \\
\hline SUM & 1 & 3 & 2 & 3 & 8 & 23 & 79 & 84 & 72 & 140 & 415 & $100 \%$ \\
\hline
\end{tabular}

The united policy-making text subject constitution and analysis of dispatch number. The number of Chinese national popular science policy documents issued by two or more united departments from 1994 to 2013 was 96 items, accounting for $18.79 \%$ of the total. Among them, in the policy text of united dispatch, when giving priority to two and three dispatch subjects, the number was respectively 44 and 35, accounting for about $45.83 \%$ and $36.46 \%$; the situation that 4 and above dispatch subject united to dispatch was less, the number of 4 subject united dispatch policy was 9 items, accounting for $9.38 \%$, the number was 8 when above 4 , accounting for $8.33 \%$ of the total.

Table 2 Condition of Policy Subject of United Dispatch

\begin{tabular}{ccc}
\hline SUBJECT & Policy & PET \\
\hline 2 & 44 & $45.83 \%$ \\
3 & 35 & $36.46 \%$ \\
4 & 9 & $9.38 \%$ \\
over 4 & 8 & $8.33 \%$ \\
SUM & 96 & $100.00 \%$ \\
\hline
\end{tabular}


In the subject of united dispatch, the most times involved was Ministry of Science and Technology, accounting for $15.1 \%$ of the total, meaning the ability to cooperate with other departments in making popular science policy, Ministry of Science and Technology was the strongest. Followed was the Chinese association for science and technology, accounting for $14.25 \%$, in addition, propaganda department, ministry of education, ministry of finance as well as the development and reform commission showed terrific cooperation ability in the department cooperation, accounting for $8.83 \%$, $8.69 \%, 8.26 \%$ and $7.83 \%$. Among them, the policy-making number that MOST with association for science and technology, propaganda department, ministry of education as well as the development and reform commission was respectively $22,16,12$ and 10, meaning the above departments were also policy dispatch participants who had closest contact. What's more, no matter in separated science policy-making or united policy-making, Ministry of Science and Technology and CAST both have a stable, high frequency output, which were the main power in policy-making. In the aspect that making popular science policy separately, Ministry of Land and Resources, state Administration of Traditional Chinese Medicine, and Ministry of Agriculture were also coming out top in policy output, but not outstanding in united dispatch, which means in the aspect of cooperating with other departments they should be improved.

\section{Conclusion}

(1) The policy dispatch number has gradual and explosive combined development character

According to the time quantum of quantitative analysis, the popular science policy dispatch number has gradual and explosive combined trend since 1994, the development tendency was relatively stable from 1994 to 2005, compared with previous period, and the trend had an obvious surge from 2006 to 2013. The average annual number of published paper was 26.4 from 1994 to 2013, from which the annual number was 5.58 from 1994 to 2005 and 57.63 from 2006 to 2013, 10.32 times than previous period. It not hard to say, the historic development of Chinese popular science has a certain regularity, as the age to issue important or strategic policy documents will be the starting point of increasing number of popular science policy dispatch, in the year ensuing the dispatch number will get bigger promotion than previous year, whose relative matching policy emerge at the right moment.

(2) Policy-making subject is mainly only one department dispatch, the scale of united dispatch subject is increasing

According to the whole Chinese popular science policy subject, the scale was large, the popular science subject of China made separately was up to 42 . The number of separate dispatch was mainly issued by Ministry of Land and Resources, state Administration of Traditional Chinese Medicine, and Ministry of Agriculture. In the policy text of united dispatch, priority was given to two and three dispatch subject. Overall, the popular science policy issued in China was still mainly by separate dispatch, the number of united issued policy was insufficient, although the united policy number was not high to the proportion of the total number, but it showed a rising trend, meaning between each dispatch subject cooperation and communication was should improved.

\section{References}

[1] P. Sun and D.Y. Kong: Journal of Graduate School of Chinese Academy of Social Sciences, Vol. 37 (2014) No.3, p.120-125.

[2] Y.L. Feng, and L.J. Zhang: Value Engineering, Vol. 42 (2011) No.2, p.324-325.

[3] D.M. Wang: Science and Technology Management Research, Vol. 34 (2011) No.22, p.34-36. [4] L.Liu and J. Chang: Journal of Hechiuniversity, Vol. 30 (2010) No.4.p.1-5.

[5] S.L. Pei, L.L. Wang and D. Wu: Science Popularization, Vol. 7 (2012) No.39.p.41-48. 
[6] Information on http://www.chinalawinfo.com

[7] T.H. Feng: Science Popularization, Vol.15 (2008) No.4.p.22-26.

[8] Z. D.Jian: Design The New Mold of Policy Analysis (TongJi University of Shanghai, China, 2014), p.34.

[9] X.Ming: Design Introduction to Public Policy (China Renmin University Press, China, 2011), p. 46.

[10]W. Guo: Science Research Management.Vol. 18 (2010) No.5. p.124-130. 